\title{
El Jurado popular en Colombia en el juicio criminal ordinario. Participación ciudadana y justicia penal en Medellín (1821-1886)
}

\author{
por \\ Andrés Alejandro Londoño Tamayo ${ }^{1}$ \\ UNAM \\ alejolondono32@gmail.com
}

\begin{abstract}
Este artículo profundiza en la comprensión de la trayectoria seguida por el Jurado popular en materia de justicia criminal ordinaria en Colombia, tomando como estudio de caso el circuito judicial de Medellín (1821-1886). Su objetivo principal es explicar a partir de un estudio centrado en las tendencias de participación ciudadana y de las garantías procesales generadas por la institución en los juzgados, la manera como ésta incidió en el proceso de democratización de la sociedad y en la transformación de la justicia penal. Esta labor se sustenta en un conjunto variado de fuentes documentales, principalmente procesos penales, y en teorizaciones historiográficas críticas sobre la ciudadanía, el derecho y la justicia en el marco Latinoamericano.

Palabras Clave: jurado popular; derecho; criminalidad; historia de la justicia; poder judicial; Colombia siglo XIX; Medellín.
\end{abstract}

\section{INTRODUCCIÓN}

Este artículo analiza algunas de las transformaciones políticas y judiciales desplegadas por el Jurado popular en Medellín entre 1821 y 1886. Al tratarse de una institución no considerada por la historiografía contemporánea y sobre la que existe un amplio desconocimiento académico y social, a pesar de haberse mantenido de forma permanente en el orden jurídico de los siglos XIX y

\footnotetext{
${ }^{1}$ UNAM, Programa de becas postdoctorales de la UNAM, Becario del Instituto de Investigaciones Históricas.
} 
$\mathrm{XX}^{2}$, su estudio busca recuperar y mostrar su relevancia en la transformación de la sociedad colombiana. Con la finalidad de incidir en esa capacidad de cambio serán abordadas las prácticas y dinámicas que promovió en materia de participación ciudadana y de garantías procesales. Mediante una perspectiva que supedita el plano legal al político se pretende enfatizar la asociación del Jurado al principio democrático y caracterizar su naturaleza modernizadora en materia de justicia a partir de su aceptación y práctica social.

La cronología de estudio establecida enmarca dos modelos estatales uno central (1821-1853) y otro federal (1853-1886) ${ }^{3}$ en los que el Jurado tuvo un peso diferenciable en el orden jurídico, fue practicado en el primer caso para delitos de imprenta y en el segundo para los delitos de la justicia criminal ordinaria. El aumento competencial y de participación atribuidos al Jurado durante el Estado federal define una de las transformaciones más importantes del republicanismo colombiano de entre las operadas a mediados del siglo $\mathrm{XIX}^{4}$, porque no solo impuso una ruptura con el modelo de justicia definido para el Estado tras la independencia, de jueces y cortes circunscritos dentro de un Poder Judicial subordinado a Ley, sino que significó la entrada del derecho político de participación en la justicia que sumado al del voto aumentó el gobierno ciudadano.

Las rupturas generadas por el Jurado dentro de la cultura jurídica y política del periodo son visibles en la variada y rica documentación política y judicial de la época, y es a partir de su estudio que se sostiene como hipótesis que en Medellín el Jurado operó como contrapeso del derecho sancionado por el poder legislativo debido a su capacidad para sancionar veredictos soberanos. El equilibrio del Poder Público fomentado por el Jurado tuvo una concreción en la práctica judicial a partir de una tendencia de sanción de los paneles populares que se caracterizó por la omisión y anulación de tipificaciones delictivas y por la reducción punitiva de la codificación. Por tal hecho se argumenta que el Jurado constituye un indicador de que en el proceso de modernización de la justicia en Colombia se instituyó un modelo de justicia basado en la participación ciudadana que moldeó y limitó los excesos del modelo del absolutismo jurídico. Por este último se entiende un modelo jurídico-político que instituyó la Ley como Derecho único del Estado y equivalente de justicia, partiendo de

${ }^{2}$ El juicio por Jurado en Colombia en materia criminal conocido también como el juez de hecho o juez de conciencia se mantuvo en vigor de forma ininterrumpida en el orden jurídico durante 170 años, siendo derogado a través del artículo 573 del decreto 2.700 de 1991.

${ }^{3}$ Denominaciones estatales durante la cronología de abordaje: República de la Gran Colombia (1821-1831), República de la Nueva Granada (1831-1858), Confederación Granadina (1858-1863), Estados Unidos de Colombia (1863-1886).

${ }^{4}$ Camacho Roldan, 1946: 57-63. Jaramillo Uribe, 2001. 
la lógica contractualista que consideraba la Ley como producto del pueblo a través del gobierno representativo ${ }^{5}$.

En el marco de construcción estatal colombiano de la primera mitad del siglo XIX el proceso de definición de un aparato judicial en articulación con el republicanismo fue polémico por el contraste entre los dos modelos de administración de justicia imperantes: Jueces letrados-codificación y Jurado. Es de indicar que estos modelos eran las únicas opciones disponibles dentro del imaginario jurídico del occidente del periodo revolucionario. Las elites políticas dieron primacía al primero en correspondencia a la concreción del marco constitucional legicentrista ${ }^{6}$ definido para el naciente gobierno. Tal acto resultaba natural en la medida en que el nuevo constitucionalismo requería de jueces sin arbitrio, aplicadores estrictos de ley, sumisos al mandato legislativo. Sin embargo, tal elección no significó ni la anulación del Jurado del orden jurídico (en tanto para el periodo no se entendía libertad de imprenta sin jurado), ni tampoco evitó un arduo debate entre los publicistas y gobernantes debido a la pronta comprensión respecto a que un modelo en el que predominaba el Poder legislativo entre los Poderes generaba repercusiones directas en la aplicación y distribución del derecho. Debido a los conocimientos sobre el Jurado que empezaron a irrigar la cultura jurídica como ha podido identificarse para el caso colombiano, los liberales advirtieron el peligro derivado de un otorgamiento exclusivo al Poder legislativo para crear ley, sin contrapeso de otro Poder aun cuando los dictámenes de aquél resultaran anticonstitucionales ${ }^{7}$. En la Nueva Granada, el rápido avance del ideario del absolutismo jurídico en materia penal (Ley orgánica de tribunales 1834, Código penal 1837, código procesal penal 1846), no tuvo la operatividad esperada, de allí que el debate social proyectara el Jurado a partir de 1850 como un medio alternativo que podía ofrecer mayores garantías de justicia.

De esta manera se plantea que durante el proceso de construcción del Estado-nación colombiano a pesar del rápido inició del ideario del absolutismo jurídico y sus instituciones este perdió fuerza en materia peral por su ideología homogeneizadora y sus consecuencias de exclusión social, severidad punitiva y elitismo. El Jurado fue aunado a un modelo de justicia letrada fundado en Cortes superiores, inferiores y juzgados de Circuito. Este proceso define una integración compleja y contradictoria pero funcional -si se tiene en cuenta que

\footnotetext{
5 Respecto a la categoría de absolutismo jurídico: Grossi, 2003. Speckman, 2006. Hespanha, 2002. Fioravanti, 2003; 2004.

${ }^{6}$ La obra de Florentino González es un exponente de la crítica en Colombia, González, 1840; 1869a; 1869b. Sobre la categoría de legicentrismo ver Fioravanti, 2003.

7 Clavero, 1991; 1997.
} 
el jurado debía ser operado por los juzgados de circuito- de dos modelos que se coordinaron para lograr una mejor garantía de justicia dentro de un orden plural en el que imperaban múltiples comprensiones del derecho. Su funcionalidad obedecería a una estructuración asociativa antes que jerarquizada realizada por el Poder Legislativo, encargado de la configuración de los modelos de Jurado y de su asocio con la Ley y las instituciones políticas. Tal Poder dispondría que la codificación por la que podía ser incriminado un sujeto se constituyera en la norma a partir de la cual los paneles debían fallar, pero debido también a su reconocimiento de la soberanía del Jurado, en tanto representación ciudadana directa, se le otorgó la capacidad de nulificar las acusaciones, omitir tipificaciones y disminuir el rigor de la ley penal. Esta configuración que otorgó control al Estado a través del Juez letrado y otorgaba garantías a los ciudadanos incriminados a través del jurado: sorteo de jueces, veredicto plural, debido proceso, se asumió como un beneficio que debía ser practicado en delitos penales en los que podía incurrir cualquier persona y aceptados socialmente (homicidio, robo, heridas, violación, falsificación, difamación, abuso de confianza, deshonestidad, heridas leves, falta de respeto, amagos).

En la medida en que el tema historiográfico del Jurado se circunscribe dentro del tema de la ciudadanía y a que para el caso colombiano el primero no ha sido estudiado y el segundo se encuentra ampliamente desacreditado por perspectivas que sostienen la anomalía de las prácticas políticas, este artículo se nutre de enfoques desarrollados para ambas temáticas en otros espacios latinoamericanos. Respecto al tema de ciudadanía se acude a estudios explicativos de la dinamización de los espacios jurídicos latinoamericanos, deconstructores de la idea relativa a que los procesos de participación política fueron ficciones o instrumentaciones de élite para legitimar sus gobiernos, y que a partir de una reconstrucción histórica del concepto de ciudadanía contrastan el argumento relativo a que las estructuras censitarias fijadas fueron diseñadas para la exclusión en vez de para el orden ${ }^{8}$. Respecto al tema del Jurado, con la finalidad de contrarrestar los tópicos sostenidos por juristas colombianos sobre su práctica, y también de historiadores del derecho contemporáneos que niegan su potencialidad en Latinoamérica, este artículo tendrá apoyo en la historiografía del derecho y de la justicia Latinoamericana ${ }^{9}$. Dentro de esta se

\footnotetext{
8 Malamud, González e Irurozqui, 1996. Sábato, 1998. Posada-Carbó, 1996. Irurozqui Victoriano, 2005; 2008. Irurozqui y Galante, 2011. Irurozqui, Galante y Argeri, 2011. Echeverri, 2009: 45-72. Thibaud, 2003. Galante, 2010.

9 Speckman Guerra, 2005; 2006; 2007. Sala y Vila, 2012: 423-450. Clavero, 1997. Carvalho, 1999: 321-344. Arroyo Padilla, 2000:137-169. Piccato, 2010. Bonaudo, 2008: 255-280. Flory, 1986.
} 
ha planteado a partir del estudio de expedientes criminales con Jurado que la intervención de los particulares en la justicia condujo a reducir «el monismo jurídico», y que ello implica considerar prácticas de construcción de un orden jurídico pluriordenamental ${ }^{10}$.

Este artículo se contrapone a una visión estereotipada sobre el Jurado popular que arguye que éste no tuvo potencial en el contexto de construcción de los Estados republicanos latinoamericanos porque los rasgos pluriétnicos (lo que sería extensible también a los rasgos pluriregionales y pluriclasistas) eran opuestos a la estructura social homogénea requerida por el Jurado como «justicia de iguales». Según esta mirada, en la práctica judicial la justicia «saltaba por los aires» cuando sectores culturales divergentes se enfrentaban en los juzgados: no podía haber acuerdo debido a una heterogeneidad adversa a la nación de iguales prototípica de Estados Unidos o Inglaterra ${ }^{11}$. Esto sugiere que había una sociedad adversa al principio de igualdad ante la ley, y desinteresada en la impartición de una justicia proporcionada en delitos que podían afectar a todos los ciudadanos sin importar sus costumbres o grupos culturales.

En oposición a esa visión del proceso de construcción ciudadana en la que se presenta una sociedad tradicionalista este artículo profundizará en las diferentes aportaciones que la institución realizó a la cultura jurídica y política en materia de derecho procesal-penal y de participación ciudadana. Para observar tal hecho este artículo se divide en tres partes. La primera se centra en el significado del Jurado y la trayectoria ideológica que acompañó su incardinación en el orden jurídico. Se explora de qué manera fue comprendida la interacción entre el principio del Jurado -institución libre en la determinación de los veredictos- y el principio relativo a la aplicación exclusiva de la Ley uniforme y general sancionada por el Poder Legislativo. En la segunda parte se analizan las tendencias indicadas por los expedientes respecto a la aplicación de las garantías procesales durante el juicio con Jurado. Ello implica un acercamiento a las acciones desempeñadas para su cumplimiento por las autoridades judiciales y defensores. Y, la tercera parte, ofrece un acercamiento al régimen de castigo que impuso el juicio por Jurado en materia de delitos comunes. Para esta labor fueron analizados los elementos característicos de la criminalidad en Medellín y los factores procesales de los expedientes incidentes en las determinaciones de los paneles.

10 Speckman Guerra, 2006: 1411-1420.

11 Desde la historia constitucional se plantea que la institución del Jurado no tuvo potencial en México debido a la diversidad cultural de los diferentes grupos constitutivos de la nación. Esta es extrapolada a Colombia. Clavero, 1997: 106-163. 
EL SIGNO DE LA JUSTICIA DEL JURADO Y SU ENTRONCAMIENTO EN LA CULTURA JURÍDICA Y POLÍTICA COLOMBIANA DECIMONÓNICA

La trayectoria del Jurado en el siglo XIX en Colombia describe un proceso indicativo del predominio que fue ganando la institución en el orden jurídico: iniciando con una competencia para un solo delito hasta arraigarse como mecanismo de juicio de lo criminal ordinario. Esta extensión que amplio el horizonte democrático durante el periodo del Estado Federal (1853-1886) se caracterizó por la competencia del Jurado para definir las causas penales sin neutralización de juez. La demanda social de Jurado ocurrida a mediados del siglo XIX se fundó en una cultura jurídica y política dinámica, que a partir del aprendizaje derivado del republicanismo y sus instituciones asumió como necesaria la participación política en la justicia.

En el proceso de construcción de la ciudadanía el Jurado se proyectó como un mecanismo representativo que junto al voto repercutiría en la participación y el gobierno. El mismo discurso jurídico que operó para fijar la estructura censitaria del electorado en el voto se utilizó para la del Jurado. La Constitución de Cúcuta estableció un voto masculino indirecto fijando para el primer nivel (parroquial) mayoría de edad/casado, alfabetización (a partir de 1840), propiedad o condición de trabajador no doméstico. Para el segundo nivel (electores del poder ejecutivo y legislativo), fijó los mismos requisitos anteriores aunque prescribió la inmediatez del criterio de alfabetización y se aumentó el monto de renta. Estos niveles y sus cambios -siendo el segundo la norma de participación en el Jurado durante la primera mitad del siglo XIX- fueron aceptados por la sociedad del periodo debido a sus fundamentos legitimadores: razón, responsabilidad, independencia, educación, tenidos como competencias para ejercer el derecho político. La rigidez del mecanismo censitario también se entendía equilibrada por otros aspectos: en primer lugar, se asumió que la estructura electoral sería operada -teniendo presente la centralidad de la condición de vecino- en función del principio de compromiso del individuo con su comunidad, local, regional y nacional; y la definición de tal compromiso debía ser objeto de discrecionalidad local. En segundo lugar, la estructura no tenía efecto sobre la igualdad de naturaleza jurídica a la que quedaban sometidos todos los colombianos, los miembros de la nación pasaron a formar parte de un contrato constitucional en el que se eliminó el estatus jurídico por estamentos que implicaba un tipo de juicio y de reglas particulares para cada grupo.

La presencia del Jurado en el Congreso de Cúcuta de 1821 fue insoslayable debido a dos imperiosas necesidades jurídico políticas surgidas en este primer momento independiente de configuración constitucional. En primer lugar, la transformación del derecho penal del Estado, la construcción de un aparato 
racionalizado para reemplazar el ius commune; y, en segundo lugar, la exigencia de poner en marcha instituciones para fomentar la educación política de la población. A la altura de 1821 los conocimientos sobre el Jurado poseídos por los juristas y legisladores colombianos fueron ampliados mediante dos vías: la literatura jurídica extranjera ${ }^{12}$, en la que se desarrolló el debate sobre la idoneidad del Jurado vs el Juez letrado para el mejor funcionamiento del Estado representativo -que se libró en los marcos de las revoluciones Atlánticas estadounidense, inglesa, francesa e hispánica-. La otra fue la diferente legislación europea y americana en materia de Jurado. Los legisladores colombianos fueron además impelidos a la sanción del Jurado por ser justicia común de los delitos de expresión según se entendía en el periodo.

La referencia jurídica y legislativa extrajera fue determinante en la elaboración de los modelos de Jurado colombianos el de imprenta (1821-1851) y el modelo para delitos comunes (1852-1886), el análisis de las discusiones legislativas para su elaboración y sus elementos constitutivos resultantes así lo indica. Los modelos de Jurado en Colombia integraron elementos de los jurados inglés, estadounidense, francés y español. Los legisladores promotores de la institución suscribieron los dos principios por los que el jurado había adquirido su estructuración moderna en Inglaterra: la asignación de las materias de hecho a un número de individuos especialmente designados para ese objeto, diferentes a los jueces oficiales, y, la elección de éstos para realizar el encargo de jurados en cada juicio. En el occidente jurídico del periodo fue conocido que el Jurado era un mecanismo constitutivo del derecho común inglés: una institución judicial que contribuía a la definición de sus formas y límites, a la aplicación de un derecho casuístico respetuoso de la tradición ${ }^{13}$. Los legisladores colombianos también suscribieron el ejemplo estadounidense en cuanto a que la participación en el Jurado debía ser popular y no pender de una condición aristocrática-feudal como en Inglaterra ${ }^{14} ; \mathrm{y}$, aunque observaron

12 Entre las obras jurídicas extranjeras que más dinamizaron la discusión sobre el Jurado en Colombia se encontraron: Bentham, 1823. Escriche, 1844. Constant, 1820 y Tocqueville, 1837. Las dos primeras ayudaron a la configuración del antijuradismo colombiano, mientras las dos últimas lo hicieron en el juradismo. Las principales obras juradistas colombianas escritas durante el siglo XIX fueron las de Florentino González, 1869a; 1969b. Y las antijuradistas, las de Pinzón, 1839 y Real, 1839.

13 Garapon y Papadopoulos, 2006: 20-30.

${ }^{14}$ R. Phillips describió la importancia de la propiedad feudal: «No han fijado los estatutos las condiciones con que deben estar revestidos; sin embargo deben poseer bienes inmuebles equivalentes á lo menos en valor á los de los pequeños jurys, y al convocarlos se está en la práctica de no llamar sino á las personas que al mismo tiempo sean escuderos y posean bienes raices feudales [...]». Por su parte Tocqueville indicó: «Para tener derecho de ser jurado, es menester poseer una finca territorial del valor de diez chelines á lo menos de renta (Black- 
con admiración el establecimiento de requisitos como propiedad y educación rechazaron la exclusión hecha a indios y negros. Los legisladores colombianos para el modelo de Jurado de imprenta siguieron casi en su totalidad el modelo de jurado sancionado en el marco del Trienio liberal ${ }^{15}$ tanto sus elementos de garantía procesal: sorteos, recusaciones, dos paneles, soberanía del jurado en la decisión del hecho y el derecho ${ }^{16}$, como sus elementos de participación: mantuvo el criterio de capacitación propiedad/alfabetización, atribuyó al cabildo la elección de los jurados por su composición representativa.

En el siglo XIX hubo tres discursos jurídicos en torno al Jurado que difirieron en perspectivas jurídico-políticas, intereses burocráticos o prejuicios culturales. Estos discursos fueron canalizados por los partidos políticos y plasmados en los modelos de Jurado. El debate legislativo sobre el Jurado sostenido durante la primera mitad del siglo XIX tuvo como contendientes dos sectores liberales que no proyectaron una transformación del modelo. Para un sector liberal moderado el Jurado debía ser establecido paulatinamente en la medida en que empezara a practicarse para un sólo delito y la población aumentara sus conocimientos políticos. Comprendieron el Jurado como un mecanismo «judicial», su discurso enfatizó que podía contribuir a matizar elementos de la legislación del Ius commune (rigor penal, complejidad legislativa, carencia de garantías o jurisdicción eclesiástica), dejando de lado el énfasis sobre el valor político del Jurado. Este sector sostuvo que el Jurado podía contribuir a eliminar la arbitrariedad e inoperancia de los jueces según la práctica indicada tras la expansión de los juzgados de circuito a partir de 1834. Uno de sus argumentos más reiterativos fue que el Jurado era escuela política y jurídica de la población, institución que publicitaba la justicia y por tanto fundaba el control ciudadano respecto a una de las obligaciones más importantes del gobierno; estos factores podían contribuir a lograr la adhesión cívica de los ciudadanos a los ideales de conformación institucional republicana ${ }^{17}$.

Por otra parte, El sector liberal de perspectiva más conservadora indicó que la división en dos paneles de Jurado una para dar lugar a la causa y otra para calificar y graduar era enredada y daba lugar a impunidad. Su argumento

stone, lib, III. Cap. XXIII) [...] Es igualmente preciso que el scheriff forme los jurys, y que sean tomados de la lista anual y regular de los propietarios de tierras feudales existente en la secretaria del scheriff [...]». Tocqueville, 1837, 2: 490. Phillips, 1821: 11 y 196.

${ }_{15}$ Entre los textos legales sobre el Jurado discutidos en el marco del Trienio liberal que fueron adaptados por el liberalismo colombiano se encuentran: La Ley de libertad de imprenta de 1820, El Proyecto de Código de Procedimiento criminal (1821) y el Código penal (1822).

${ }^{16}$ La legislación española concedió al Juez la capacidad de impugnar los veredictos, hecho que no sucedió en Colombia. Monarquía Española, 1821.

17 Restrepo Piedrahita, 1989, vol. 3: 57 y 83. 
más reiterado consistió en afirmar que en la provincia solo había hombres ignorantes. Para ser jurado eran necesarios estudios en ciencias jurídicas y teológicas; y el Jurado no debía ser popular porque ello significaba la elección por «sorteo» de ciudadanos incompetentes como zapateros, carniceros, granjeros, albañiles, tenderos. El Jurado no podía ser juez de competencias que durante siglos habían sido jurisdicción de la Iglesia como eran las materias de imprenta, moral, penal, y no podía erigirse en juez de clérigos ${ }^{18}$.

Las dos perspectivas anteriores definieron un modelo de Jurado a nivel competencial y de participación cuya práctica se materializó en el Jurado de imprenta entre 1821 y 1851 . Ambos coincidieron en que las condiciones para ser jurado debían ser las mismas que para ser representantes: «porque si para establecer las leyes bastan las cualidades que se piden en la constitución, con estas mismas es suficiente para juzgar sobre ellas» ${ }^{19}$. Este sector sancionó como requisitos en la Ley de libertad de imprenta de 1821: ciudadanía en «ejercicio de derechos», hombre mayor de veinticinco años, residente del cantón y tener un oficio o una propiedad conocida ${ }^{20}$. El requisito de ciudadano en «ejercicio de derechos» aludía al ciudadano elector fijado en la Constitución de 1821 , y la condición de elector exigía: $1^{\circ}$ ) ser sufragante parroquial no suspenso, $2^{\circ}$ ) saber leer y escribir, $3^{\circ}$ ) ser mayor de veinticinco años cumplidos y vecino de la parroquia del cantón en la que se realizaba la elección, $4^{\circ}$ ) ser dueño de una propiedad raíz que alcance al valor libre de quinientos pesos, o gozar de un empleo de trescientos pesos de renta anual, o ser usufructuario de bienes que produzcan una renta de trescientos pesos anuales, o profesar alguna ciencia o tener un grado científico ${ }^{21}$.

El tercer discurso liberal que quebró con la anterior comprensión a partir de 1850 propuso el Jurado como necesario para promover la práctica de la soberanía popular en la justicia, un mecanismo de representación directa promotor de igualdad ciudadana. Por la fuerza de esta comprensión dentro de la cultura jurídica el legislador sancionó el Jurado como derecho político ciudadano, y

${ }^{18}$ En un debate legislativo el representante conservador Vicente Borrero planteó la imposibilidad de reunir veinticuatro hombres ilustrados en las provincias donde se estableciera la imprenta, por lo que propuso que los juicios por delitos de imprenta se dejaran a la justicia ordinaria y que ésta se encargara de consultar a un grupo de teólogos cuando los textos publicados ofendieran a la religión. Esta opinión fue compartida por José Félix de Restrepo. Restrepo Piedrahita, 1989, vol. 3: 274-277.

19 Restrepo Piedrahita, 1989, vol. 2: 72-73.

${ }^{20}$ República de Colombia, 1840, Sobre la Estencion de la libertad de la imprenta, y sobre la calificación y castigo de sus abusos, Art. 25: 101-102.

${ }^{21}$ Constitución de la República de la Gran Colombia, Título III, De las asambleas parroquiales y electorales. Artículos 12-29. Uribe Vargas, 1997: 711-714. 
amplió la participación eliminando el criterio de propiedad. Para el discurso liberal radical el Jurado era un juicio más legítimo que el del juez letrado, aunque se asumía que la institución era operativa en el marco de los juzgados de circuito y administrada por los jueces letrados. Uno de los elementos democráticos defendidos por el sector radical consistió en la atribución asignada a los paneles para modificar o anular la ley. Desde este sector se puso en práctica una comprensión «política» del Jurado consistente en que la soberanía popular en el Jurado podía modificar el derecho, sobreponerse a la codificación.

El discurso radical finalmente se plasmó en un modelo de Jurado garantista y de participación popular que se fijó como juicio en materia criminal ordinaria entre 1853 y 1886. Su articulación exigía, por un lado, la elaboración de una sumaria de investigación por el juzgado y el ministerio público, y por el otro, un juicio oral por Jurado con un veredicto a conciencia e inapelable. Este modelo fue diseñado en 1852 y fue la pauta a partir de la cual los Estados federales perfeccionaron sus modelos, adaptando la institución a los requerimientos de la práctica judicial. Establecía que jueces de circuito realizaran la instrucción sumarial, sortear el Jurado del censo, diligenciar recusaciones, y encargarse del orden de la sesión durante el juicio oral hasta la sentencia. La estructura del Jurado mantuvo en algunas ocasiones los paneles de acusación y calificación, y su atribución máxima radicó en su capacidad de sanción sobre el hecho y el derecho, es decir, sobre la comisión del delito y su autor y la graduación de la pena ${ }^{22}$.

El Jurado se dispuso por tanto para ser un motor político en la sociedad por ser jurisdicción de los delitos severamente castigados por el Estado y por involucrar a la población en su conocimiento, y ello implicó la definición de dinámicas y tendencias en la aplicación del castigo. En la extensión del Jurado incidieron otros motivos como su facultad para cerrar terminante los procesos a través de su veredicto inapelable. También incidió una necesidad social de poner en práctica el principio del sorteo para la elección, reproduciendo al caso uno de los principios esenciales de la democracia política en tanto que el sorteo ampliaba la igualdad de participación en los cargos públicos.

La amplia discusión y la práctica en torno al Jurado durante el periodo de estudio indica su incidencia en el incremento de la cultura jurídica y política de la población. En tal hecho se reconoce que el Jurado fue entendido por la sociedad como una institución inherente a la democracia representativa, sin la que ésta no podía tener desarrollo pleno. El Jurado se convirtió, por tanto, en un elemento indicativo de que la cultura jurídica aceptó la pluralidad jurídica

${ }^{22}$ Ver la estructura procesal diseñada para los modelos en Londoño Tamayo, 2013: 75-112. 
y judicial impulsada por aquél, y que la modernidad en la justicia no sólo se comprendió como el complimiento estricto del Derecho sancionado por el Estado $^{23}$.

\section{Los elementos garantistas de la Justicia del JuRAdo DURANTE Su APliCACión en el JuzGado de CIRCUIto de la CIUdAD dE Medellín}

En el marco de construcción del Estado republicano la fijación de una nueva legislación procesal-penal fue una prioridad para el nuevo gobierno por considerarla central para restablecer el orden y por ser una fuente de legitimidad. Existía una urgencia por matizar el exceso de las penas como la de muerte cuando se trataba de difamación, la dilación procesal y la carencia de garantías a los incriminados. Estos factores atribuidos al Ius commune a partir de 1821 fueron relacionados con la justicia penal letrada durante 1850 y ello impulsó la propuesta de introducción de un Jurado con amplias competencias para matizarlos ${ }^{24}$. El diseño del modelo de Jurado para delitos criminales comunes de 1850 y que se mantuvo en los estados regionales implicó una conexión con las instituciones y con la legislación procesal-penal sancionada durante la primera mitad del siglo: primero, el Jurado requería de las labores de elección realizadas por el cabildo y de las de ordenación durante el trámite procesal realizadas por el juez de circuito; segundo, frente a lo penal el Jurado debía tener como referente de aplicación la legislación codificada, aunque le atribuyera la soberanía del veredicto; y, tercero, en materia procesal, el Jurado posibilitaba construir un diseño procesal mixto, integrador de Jurado y sus mecanismos y de la investigación sumarial ejecutada por el juzgado de circuito ${ }^{25}$.

Atendiendo a lo anterior, este apartado se centra en explicar las dinámicas de aplicación de las garantías procesales del Jurado: la elección de ciudadanos para el acto, el sorteo, la recusación y el veredicto. El estudio se ha basado en un corpus documental de juicios con Jurado de doscientos cincuenta juicios

${ }^{23}$ Garriga y Lorente, 2007. Morelli, 2011: 27-47.

${ }^{24}$ Proyecto de ley Adicional $i$ reformatoria de las que organizan el poder judicial $i$ el procedimiento civil, criminal $i$ de responsabilidad, Archivo General de la Nación, Colombia (en adelante AGN), Cámara de Representantes, Informe de comisiones 1852, tomo V. Senado, Proyectos de ley negados y suspendidos indefinidamente, tomo II. ff: 036-053. Solicitud de reforma de la ley de 1851 y de establecimiento del jurado para diversas causas criminales para el que se agrega un cuaderno con un modelo para la Nueva Granada, La Galera, Moreno, Casanare, 20 de diciembre de 1851, AGN, Cámara, Negocios Judiciales, Informes de comisiones, Peticiones de las Cámaras provinciales, tomo IV, 1852, ff. 80-94.

${ }^{25}$ República de Colombia, 1848. 
por delitos de imprenta y delitos comunes tramitados entre 1821 y $1886^{26}$. También se tratará de profundizar en la función de las autoridades en la aplicación de las tres fases del proceso: fase de instrucción, fase de defensa escrita y juicio público con Jurado. En la primera debía llevarse a cabo la investigación que fundamentaba la acusación contra el reo o que inducía el sobreseimiento, terminaba con un auto de acusación emitido por el juez de circuito en acompañamiento con el ministerio fiscal. En la segunda asistía el defensor letrado o en su defecto el empírico, a quienes correspondía una defensa escrita y oral. En la tercera tenía aplicación todo el mecanismo del Jurado, el sorteo, la recusación y el juicio público y oral ${ }^{27}$.

El Jurado de imprenta dinamizó la participación ciudadana en las localidades, y el Jurado para delitos comunes terminó por definir un mecanismo que amplió notablemente la participación y tuvo que ordenarla mediante el control de censos por parte de los cabildos y su orden de elección y llamado por parte de los jueces. Respecto a la garantía de elección de los ciudadanos el análisis de los documentos ha permitido captar las diversas labores realizadas por el cabildo para su aplicación. Se encargó de elegir, confeccionar listas de Jurado y publicitarlas en los periódicos de la provincia bajo el imperativo de castigos administrativos por omisión ${ }^{28}$. Los cabildos realizaron censos de vecinos con los requisitos para participar en el Jurado, documentos cuya ampliación cuantitativa permitía que los cabildantes hicieran rotar cuatro listas de jurados durante el año con un promedio de ciento cincuenta ciudadanos por lista ${ }^{29}$. La elección según pudo establecerse a partir de los expedientes judiciales y de las listas recayó tanto en ciudadanos que formaban o tenían vínculos con las familias notables, como en ciudadanos pertenecientes a sectores medios y bajos ${ }^{30}$. El Juicio por Jurado se expan-

${ }^{26}$ Se parte de un amplio corpus de expedientes criminales con Jurado compilados principalmente en el Archivo Histórico Judicial de Medellín, con sede en la Universidad Nacional, sita en Medellín, Antioquía (en adelante AHJM) y del Archivo Histórico de Antioquia, también en Medellín, Antioquía, Colombia. Para esta investigación también se utilizaron expedientes del AGN.

${ }^{27}$ República de Colombia, 1851. Estado soberano de Antioquia, 1857.

${ }_{28}$ Expediente Criminal Contra el Cabildo de la Ciudad de Medellín, 1850-1851, AHJM, $\mathrm{n}^{\mathrm{o}} 2435$, f. 66. Los miembros del cabildo fueron condenado con tipificaciones como la 546 del código penal, que indicaba destitución del cargo y pena de cárcel, por no formar las listas de jurados y realizar su efectiva publicidad

${ }_{29}$ Ver listas en: El constitucional de Antioquia de Medellín, publicadas durante los meses de diciembre de 1857, 1858 y 1859. Algunos números importantes: $n^{\circ} 144: 1-8 ; n^{\circ} 145$ : 1-3; $\mathrm{n}^{\circ}$ 147: 1-2; $\mathrm{n}^{\circ} 149: 1-5 ; \mathrm{n}^{\circ} 243: 1-7$.

${ }^{30}$ Del análisis del corpus establecido resultó que algunas de las familias con mayor participación en el Jurado fueron los extensos núcleos familiares de los Restrepo y los Arango. Por 
dió con el juzgado de circuito por los cantones y pueblos multiplicando la representación en la justicia.

Los expedientes judiciales tramitados indicaron que los jueces realizaron el sorteo de forma estricta para cada juicio para garantizar al incriminado no ser juzgado por un tribunal fijo sino por un igual ante la ley. El análisis detenido de los sorteos indicó que se realizaron de forma ordenada a través de mecanismos como urnas y balotas y otros mecanismos de transparencia ${ }^{31}$. Las reiteraciones de los sorteos no fueron comunes, y cuando los hubo no significaron un retraso de los procesos o la impunidad, aunque cuando tuvieron lugar significaron para los jueces el trabajo de realizar un nuevo acto de sorteo que exigía: notificaciones, programación de nuevos sorteos y reconocimientos.

En cuanto a la garantía de recusación de los jurados los expedientes indicaron al igual que para el caso anterior que se trató de un derecho de estricto cumplimiento por parte de los jueces de circuito. El escribano pasó regularmente una hoja con una lista de siete jurados más cuatro suplentes al incriminado y al fiscal para que señalaran los recusados. La recusación resultó efectiva para los incriminados sobre todo cuando se aplicó sobre sujetos con los que éstos diferían política o ideológicamente, o que podían ser del mismo bando o compartir principios con el contendiente. Recusar no era un acto trivial para los incriminados toda vez que la absolución podía lograrse con tres votos a favor de siete, de entre los emitidos por el panel para la sanción del veredicto.

El estudio de la garantía procesal de asistencia de defensor indicó que el nombramiento gratuito de profesionales fue limitado por el alto número de expedientes tramitados y la carencia de abogados. La carencia repercutió en el incremento de los defensores empíricos. Ambos tipos de defensores alegaron en casi todas sus participaciones elementos atenuantes de las penas, a propósito de incidir en las graduaciones penales atribuidas a los jurados con base en los elementos agravantes y atenuantes de los delitos. En sus defensas escritas los abogados crearon estrategias utilizando pruebas testimoniales para probar buena conducta del incriminado, desvincularlo del hecho delictivo o lograr la incriminación del denunciante o un tercero. A partir del estudio de estas estrategias en el marco de los procesos pudo identificarse una imagen

otro lado, entre los apellidos de sectores medios indicados en los expedientes se observaron: Bravo, Hernández, Toro, Naranjo, Mora, Sánchez, Muñoz, Valle, Peláez, Chavarriaga, Mazo.

${ }^{31}$ En el pleito sostenido entre Pantaleón Arango y Luis Llorente se repitieron cinco sorteos de jurados, por tanto el alcalde ordinario en aras de mostrar la transparencia del procedimiento de sorteó utilizó a un niño para que sacara las cédulas de la vasija en la que estaban depositadas. Expediente criminal contra Luis Llorente por el delito de libelo infamatorio denunciado por el Lic. Pantaleón Arango, Bogotá, 1823, AGN, Fondo República, Asuntos Criminales, leg. 53, ff: 708-731. 
de los defensores que no se corresponde con el estereotipo presentado en textos narrativos, en los que aquellos son recreados como rábulas tramposos, mancomunados con los jurados y las autoridades judiciales ${ }^{32}$. Los abogados encontraron lagunas legales en las leyes de jurados, debatieron conceptos de jueces y fiscales, enfrentaron disputas jurídicas en torno al Jurado y utilizaron en los juicios estrategias retóricas complejas. En algunos casos también cometieron delitos como falso testimonio, manipulación de versiones y compra de testigos, como se observó en las defensas adelantadas por Rafael Calle ${ }^{33}$.

El análisis de la garantía del veredicto del Jurado indicó una práctica regular de las formas diseñadas por el legislador para asegurar su cumplimiento. Los jueces de circuito realizaron la ordenación de tribunales plurales para presidir los juicios, y la discusión y elaboración de los veredictos fueron realizadas a menudo en cuarto privados, el público tuvo la oportunidad de presidir, y a menudo el tumulto era formado por testigos. Algunos juicios debido a su notabilidad fueron desarrollados en plazas públicas, iglesias y alcaldías. El veredicto de los jurados tuvo en la opinión pública un control según el debate reflejado en la prensa, relativo a denuncias públicas contra jurados y paneles, promoción del veredicto imparcial y las narrativas de los juicios. El veredicto fue apelado con escasa frecuencia por cuestiones de errores de procedimiento y por injusticia notoria, aunque lo último solo empezó a ser posible a partir de la década de 1860 cuando se estableció la posibilidad de apelar ante el Tribunal de Distrito sobre la resolución del Jurado. En cualquier caso, los tribunales superiores a quienes correspondía ponderar la validez del veredicto tenían como máxima atribución la convocatoria de un nuevo tribunal cuando se determinaba un error. En la ciudad de Medellín se ha observado en sentencias del Tribunal que dentro de este existía la opinión de considerar el veredicto como soberano, así resultara polémico frente al proceso y aún con la atribución otorgada por la ley para revocarlos ${ }^{34}$.

Los veredictos se consignaron en cuestionarios que fueron diseñados por los legisladores con la finalidad de captar una respuesta precisa sobre la comisión del hecho delictivo, el autor y el castigo. El análisis de los expedientes ha indicado la instalación de una práctica consistente en la sanción

32 Córdovez Moure, 1946: 169-186.

${ }^{33}$ Las defensas realizadas por Calle se caracterizaron por presentar largas listas de testigos y estrategias que buscaban la distorsión. Calle apeló en diferentes ocasiones a los errores producidos en la organización y producción de veredicto del Jurado. Expedientes del corpus en los que participó como defensor: 1937, 2429, 9591, 13082, 13093, 2454, todos ellos en el AHJM. Tuvo también presencia como defensor en crímenes connotados como el de la Aguacatal. Muñoz Fernández, 1874.

${ }^{34}$ Expediente Contra Nepomuceno Rodríguez por heridas, AHJM, nº. 2098, ff: 50-67. 
de la existencia del delito de forma paralela a la omisión del dato de su autor, hecho que dio lugar a un veredicto denominado en la época como contradictorio. Este tipo de veredictos se presentaron de manera reiterativa, y fueron un mecanismo cuya finalidad fue la absolución de los incriminados. El legislador del Estado de Antioquia en aras de evitar absoluciones erróneas de los Jurados establecieron cuestionarios en los que regularon con más precisión la manera como debían ser resueltos. Por ejemplo, se estableció que si sancionaban la comisión del delito necesariamente tenían que sancionar la culpabilidad del autor ${ }^{35}$.

\section{Las políticas de CASTigo de los JuRAdos en Materia CRIMINal ordinaria EN LA CIUDAD DE MEDELLín (1851-1873)}

En este apartado se insistirá en que la institución del Jurado dinamizó la democracia porque posibilitó una representación en la Justicia que tornó en el establecimiento de políticas de castigo. Estas se concretaron a través de la omisión y anulación de tipificaciones y la reducción de la penalidad. La crítica del positivismo penal iniciada a partir de la década de 1870 respecto a la incapacidad social que derivó en la impunidad de los veredictos puede matizarse a partir de los expedientes criminales, que indican que detrás de la práctica del Jurado hubo una dinámica procesal compleja, que en todo caso refleja que la población se resistió a una homogeneización legal que podía derivar en una mayor exclusión pública ${ }^{36}$.

En la ciudad de Medellín y en toda la jurisdicción del juzgado de circuito el perfil de los incriminados por delitos comunes fue el de un hombre/mujer joven que desempeñaba un oficio de escasa relevancia social y económica y que generalmente era analfabeto. Las mujeres, aunque con menor frecuencia incriminadas, fueron procesadas sobre todo por delito de hurto. Asimismo, el sujeto criminal pertenecía fundamentalmente a la clase popular que iba engrosando la ciudad durante la segunda mitad del siglo XIX y solía residir en lugares considerados conflictivos como Guanteros o el Cuchillón. En ellos la policía hacía rondas frecuentemente debido al apremio de las demandas ${ }^{37}$. Los delitos contra la propiedad los comprendieron robos y hurtos de medianas y pequeñas cuantías cometidos en vía pública, locales comerciales y casas

\footnotetext{
${ }^{35}$ Ver la historiografía jurídica sobre el Jurado y su abordaje de las leyes de procedimiento: Jaramillo. 1935. Infante, 1892. Jiménez, 1940. Quiñonez Neira, 1952. Arias, 1954.

${ }^{36}$ Martínez, 1895.

${ }^{37}$ Melo, 1988.
} 
de particulares, el hurto de reses y caballos; y, en menor medida, los robos cometidos por banda armada. En cuanto a los delitos contra las personas el de mayor frecuencia fue el de lesiones que usualmente estuvo vinculado al consumo de alcohol. En no pocas ocasiones las agresiones verbales y físicas derivaron frecuentemente en riñas callejeras que requirieron la intervención de la autoridad. La criminalidad empezó a crecer y a modificarse durante la segunda mitad del siglo XIX como es indicado por el comentario judicial, la estadística oficial y los tipos de procesos compilados en los archivos, dejando de ser el delito de injurias uno de los más recurrentes para dar paso a delitos contra las personas y la propiedad ${ }^{38}$. En el aumento de la criminalidad en Medellín incidieron diferentes factores: el aumento demográfico, sobre todo de sectores con marcadas carencias socio-económicas; el ambiente bélico producido por las guerras civiles; las tensiones viejas y nuevas propias de un contexto social marcado por su diversidad cultural; $y$ una fuerte jerarquización socioeconómica.

A partir de los expedientes puede reconstruirse tanto el perfil del criminal peligroso, como el del sujeto que se vio inmiscuido en un acto delictivo pero que no tenía un perfil para ser tenido como aquél. Los primeros fueron incriminados por delitos graves como homicidio, utilizaron la fuerza y se sirvieron de armas para la comisión de delitos, tenían historiales delictivos, y a menudo crearon estrategias para distorsionar las investigaciones que se hicieran en su contra $^{39}$. La comisión de un delito frecuente como el de delito de heridas tenido por grave por la legislación penal, no tuvo necesariamente una correspondencia con un sujeto criminal peligroso, en su comisión se vieron envueltas personas cuya agresividad estuvo determinada por el alcohol y las rencillas.

\section{El JuRAdo y los Delitos CONTRA LA PROPiedad}

El cuidado de la propiedad se priorizó de forma especial desde el inicio de la independencia quedando ello expresado en la variedad de la tipificación delictiva y en el rigor penal fijado para delitos como robo, estafa, hurto, falsificación o bandolerismo. Al constituir uno de los principios básicos sancionado

${ }^{38}$ Los delitos de heridas y riña fueron junto con los delitos contra la propiedad los que más frecuencia de comisión presentaron en las estadísticas de los años 1836 y 1846. A pesar de éstas en los archivos reposa un número significativo de denuncias por calumnia e infamia tramitados durante la primera mitad del siglo XIX, tipologías delictivas que habían tenido una frecuencia notable durante el siglo XVIII. Ver: Secretaría de Relaciones Exteriores, 1846, Primera parte, población e instituciones, 177-185, 188-196. Melo, 1988. Patiño, 1994.

39 Expediente criminal contra Pablo Osorio por la muerte de Alejandro Aguilar, Medellín, 1858-1861, AHJM, Sección juicios criminales, caja 117, nº 2462, ff: 63-64. 
por la asamblea constituyente de 1821, la protección de los bienes pudo servir incluso para justificar la sanción posterior de medidas despóticas como la pena de muerte para los delitos de robo y hurto en los que se utilizaran armas, aunque tal medida estuviera en contradicción con el discurso de disminución del rigor penal ostentado por el gobierno en otros ámbitos ${ }^{40}$. En el Código Penal de 1837 el rigor de las penas se mantuvo en los delitos contra la propiedad, siendo los trabajos forzados y el presidio los castigos más habituales.

En Medellín, el único tipo de robo sobre el que se observó una tendencia a la condena y a una graduación punitiva rigurosa fue el de abigeato, sobre todo cuando se probaba de forma estricta la culpabilidad de los incriminados. Por ejemplo, en el expediente seguido contra Francisco Garcés por el delito de hurto de un caballo perteneciente a Francisco Muñoz se presentaron diferentes pruebas en su contra. Las declaraciones sumariales mostraban que Muñoz supo del robo del animal cuando lo vio conducido por un vecino, Alberto Quintero, quien le refirió que lo había recibido de Garcés como parte de una deuda. El incriminado, quien afirmó desempeñarse como carpintero, alfabetizado y casado, indicó tras su detención los nombres de algunos testigos que podían atestiguar su pertenencia del caballo. Sin embargo, esto fue desmentido ${ }^{41}$ y se confirmó la estafa de la venta a Quintero. El fiscal y el juez reforzaron su acusación contra el incriminado basándose en un antecedente penal que presentaba el denunciado por un delito de abigeato. En su defensa el incriminado nombró como defensor a Manuel Posada Arango, que presentó un interrogatorio de conducta y solicitó al fiscal la exclusión del antiguo expediente contra Garcés, lo que le fue negado. En el juicio, al que asistió el defensor, el Jurado respondió al cuestionario presentado por el juez indicando la comisión del delito fijado en el artículo único de la ley de 2 de junio de $1846^{42}$. El juez, a quien correspondía la graduación de la pena, sancionó el segundo grado correspondiente a una pena de dos años y tres meses de presidio, costas procesales, resarcimiento de daños, fiador de conducta y sentencia pública.

En comparación con el delito de abigeato castigado y graduado por el Jurado en segundo grado, otros delitos como hurto de joyas, hurto de dinero $\mathrm{y}$ estafas fueron graduados en tercer grado. En los expedientes relativos a estos delitos también se observó una tendencia a la absolución por dudas en

${ }^{40}$ República de Colombia, 1840: 525-524, Decreto del 3 de mayo sobre procedimiento en las causas de hurto y robo.

${ }^{41}$ Expediente contra Francisco Garcés, Medellín, AHJM, 1858, caja 117, nº 2440, ff: 26-30.

${ }^{42}$ Nueva Granada, Leyes y decretos espedidos por el Congreso Constitucional de la Nueva Granada en el año de 1846, Bogotá, 1846: 83. Se trató del artículo aplicable al caso de abigeato. Artículo único reformado al artículo 818 del Código Penal. 
la demostración criminal o como consecuencia de una defensa rigurosa del abogado. En la causa contra María Josefa Anjel, una joven cocinera de diez y nueve años, madre soltera y analfabeta, las autoridades ordenaron, a pesar de su confesión inmediata cuando fue detenida, la realización de algunas de las vistas que resultaron de la declaración de Ramón Vélez el denunciante. Este último, un comerciante casado y alfabetizado denunció que Joaquina Posada y Mariana Mejía le habían requerido una suma aproximada de sesenta pesos en concepto de unas velas y unos dulces y que él ya se la había entregado a su empleada para que la abonara. A esto se sumó la acusación de otra mujer, Mercedes Arboleda, que refirió que la incriminada le había solicitado también a cuenta diez pesos de tabaco en rama. En el juicio, a pesar de que el juez Víctor Molina presentó tres cargos por estafa, delito cuya tipificación indicada en el artículo 845 era rigurosa, el Jurado sancionó la culpabilidad solo en dos casos y el juez a quien correspondía establecer el grado de la pena se encargó de sancionar el tercer grado y de fijar en la sentencia una condena de prisión de dos meses. La incriminada era madre que velaba por el cuidado de sus hijos a través de su oficio, las referencias de buena conducta, y la estrategia de defensa fueron importantes en el fallo.

\section{EL JURADO Y LOS DELITOS CONTRA LAS PERSONAS}

Los delitos de heridas y riñas tuvieron una tipificación rigurosa en el Código penal de 1837 fundada en el razonamiento moral y jurídico relativo a los males que provocaban a los sujetos y la sociedad. En los delitos de heridas las leyes establecían una relación entre la intensidad de la pena y el daño físico causado, siendo medido o determinado este último a partir de la incapacidad para trabajar sufrida por el agredido. La pena máxima se fijó para el caso en que el herido resultara lesionado de por vida por la pérdida de órgano, siendo equivalente en intensidad punitiva a la de un delito de homicidio involuntario.

El corpus estudiado para los delitos de heridas graves indicó una tendencia hacia el veredicto condenatorio en los casos que no se presentaban dudas sobre la comisión del delito y su autor. Estas condenas fueron graduadas en su mayoría con el tercer grado. Tal inclinación de los paneles de Jurado pudo haberse derivado del rigor punitivo establecido en la ley para delitos de heridas, o también, y en contraste con el legislador, en la escasa valoración social que tuvieron tales delitos. Un ejemplo de esta tendencia se observa en el pleito entre Bautista Arango y Florian Peña. Estos se encontraban apostando en un garito hasta que un desacuerdo generó una grave agresión con puñal que incriminó al primero. El detonante del conflicto había sido el impago de una apuesta. De 
ocho testigos, dos declararon haber visto que el agresor sacó de su carriel el cuchillo con el que ejecutó el acto, otros realizaron declaraciones menos precisas como haber visto el acto pero no el arma. El incriminado, mayor de edad, casado y de profesión sastre y escribiente, expondría una versión inverosímil: haber empujado a Florián Peña contra un escaparate del que sobresalían unos clavos, que fueron las causantes de las heridas. Las autoridades, el juez Víctor Molina y el fiscal José María Ramírez Gómez, sancionaron el auto de proceder por heridas contra el incriminado. Éste nombró como defensor al abogado Emiliano Restrepo, quien presentó interrogatorios de conducta y defensa, y solicitó a testigos presenciales como el médico Pedro Uribe Mejía, quien contradijo al abogado, al responder que sabía que el incriminado era pobre pero que no le constaba que fuera ignorante, ni pacífico o enemigo de peleas. En la sesión de juicio, el juez preguntó en el cuestionario por la comisión del artículo 671, lo que fue ratificado por el Jurado. La graduación del delito fue el tercer grado.

Según lo analizado en un grupo de expedientes por heridas el Jurado modificó el delito propuesto por los jueces en los cuestionarios. Se presentó en casos para los que se exigieron condenas rigurosas como la tipificada en el artículo 669. Éste sería modificado por un artículo también relativo a heridas pero de menor intensidad punitiva como ocurrió en el caso contra Nepomuceno Rodríguez por quebrar el brazo de su suegro, un anciano mayor de ochenta años, a quien los peritos dictaminaron inutilidad absoluta ${ }^{43}$. El juez preguntó en el cuestionario por la comisión del delito 699 relativo a la pérdida de un órgano de por vida a lo que el Jurado respondió negando la acusación solicitada. Tras ello el juez preguntó qué delito creía entonces el panel que se había cometido, a lo que éste declaró por unanimidad que el de maltrato de obra definido en el artículo único de la ley de 31 de mayo de $1849^{44}$. La rigurosa pena por heridas graves, similar a la de homicidio involuntario, no era justicia cuando se trataba de un anciano jubilado que había iniciado el conflicto. Estos expedientes por delito de heridas indican que los paneles no sancionaban con rigor a los incriminados por lesiones leves. Este tipo de actuación pudo ser desfavorable a las víctimas si se tiene presente la posibilidad de error pericial. En el proceso contra Rafael Hernández el Jurado emitió un veredicto de culpabilidad solo por el delito de irrespeto al alcalde de Copacabana, pese a que la investigación de los hechos probó que el incriminado había cometido delitos de mayor gravedad, como una tentativa de heridas a funcionarios públicos y

${ }^{43}$ Expediente Contra Nepomuceno Rodríguez, AHJM, nº. 2098, ff: 50-67.

${ }^{44}$ Expediente contra Ramón Torres y Jesús Beltrán, AHJM, nº 13082, ff. 139-144. Se trató de la sentencia en la que el jurado se equivocó en la indicación del mes en que fue sancionada la ley, siendo el mes correcto marzo. 
particulares. La investigación sumaria indicaba que el comisario y el alcalde intentaron detener a Rafael Hernández cuando se peleaba borracho en la plaza de Copacabana, pero no lo lograron dado su nivel de agresividad. Hernández extrajo el cuchillo de una tienda y persiguió el comisario hasta las afueras del pueblo ocasionando lesiones a Cruz López, uno de los vecinos que trató de someterlo. De regreso a la plaza, Hernández se situó frente a la alcaldía para insultar al alcalde, le gritó que se «ganaba la plata de valde» y que era un tolerado por el pueblo. El juzgado de circuito sancionaría un auto de proceder riguroso con base en estos hechos de «Tentativa de heridas e irrespetos a dos funcionarios públicos, como también por el de tentativa de heridas a Cruz López». El abogado Hermenegildo Botero realizó una defensa rigurosa que posiblemente fue uno de los elementos influyentes en el veredicto flexible del Jurado $^{45}$ El juez Víctor Molina presentó al jurado cinco series de cuestionarios de los que cuatro eran relativos a la comisión de los delitos, mientras que la última serie consistió en una pregunta final en la que solicitó a los jurados que señalaran el delito cometido en caso de considerar que no era ninguno de los indicados en las series previas. El Jurado sancionó un veredicto en el que se culpó al incriminado por el delito de irrespeto contra el alcalde. El juez graduó la pena en tercer grado y falló cuatro días de cárcel.

El estudio de los expedientes por heridas indicó una tendencia de graduación baja de la pena a pesar de la gravedad, el uso del hacha y el machete no constituyeron agravantes. Los delitos sexuales y otras violencias también tuvieron poca posibilidad de ser penados, lo que resultó en detrimento de las mujeres. Así, por ejemplo, el comisario de policía de Medellín, Rafael Vélez recibió un informe de su homólogo del distrito de la Estrella, en el que se le solicitaba la captura de Francisco Velásquez alias «Parranda», quien se encontraba en Medellín «sin oficio ni beneficio» y habiendo dejado abandonados a su esposa e hijos. El comisario en compañía del alcalde parroquial de Medellín $\mathrm{y}$ algunos comisarios procedieron a investigar las denuncias dirigiéndose al lugar de vivienda del acusado. Allí recibieron una nueva denuncia por parte de Andrea Londoño, que indicó que Velásquez la acosaba constantemente hasta el punto de verse obligada a poner la denuncia en secreto por temor; también expresó que se encontraba amancebada con él por la represión y los

${ }^{45}$ Francisco Betancur contra Rafael Hernández, AHJM, n 2455. f. 28. Presentó un interrogatorio de conducta y otro de defensa, resultando de ambos declaraciones favorables para el incriminado. Los testigos corroboraron, por ejemplo, la tesis del abogado respecto a la inutilidad del cuchillo utilizado por el agresor «El cuchillo que tiene en su tienda le sirve para cortar tocino, queso, carne, i panela, no es bueno i que no tenia buena punta, i que es imposible que Rafael Hernández pueda herir a un individuo que salía corriendo a la carrera de huida pues no lo alcanzo». 
castigos a los que la sometía. A pesar de la denuncia, las autoridades dieron más crédito a la declaración de un testigo que refirió que la denunciante y su agresor «vivían sin estar casados y de forma pública» y sancionaron un auto de proceder contra ambos por el delito de «amancebamiento», omitiendo con ello una investigación por maltratos o violencia. Aunque la defensa del incriminado se centró únicamente en lograr la exculpación por el delito de amancebamiento, la de la denunciante mantuvo una línea de acusación por maltratos y acoso El Jurado, sin embargo, sancionó un veredicto que absolvió a ambos del delito de amancebamiento.

De igual manera, en el expediente contra Isidoro Restrepo por el delito de expresiones y acciones deshonestas sobre María de Jesús Restrepo las autoridades omitieron investigar un delito de violación que resultaba fundado en las denuncias y declaraciones de un testigo presencial y de crédito público. El Dr. Tomás Uribe denunció un acto de fornicación aunque de sus exposiciones frente a las autoridades se deducía la violación de una mujer menor. El fiscal solicitó al funcionario de instrucción que se le practicara un peritaje a la mujer para determinar su estado, aunque sin precisar el tipo de evaluación que debía hacerse. Los peritos valoraron únicamente si las expresiones y acciones ejecutadas por Restrepo y denunciadas por Uribe eran inmorales. Los peritos las consideraron así, no se realizó una valoración física de la mujer, y las autoridades no facilitaron a la mujer los peritajes ni en presentar una incriminación por delito sexual. El incriminado nombró un abogado que solicitó pruebas para demostrar el estado de embriaguez de su defendido la noche de los hechos, y aceptó sin vacilación que el delito cometido por su cliente fue el de «intento de apuñalar» a la mujer como consecuencia de la disputa que sostuvieron. En el juicio el juez Pascucio Uribe preguntó por la comisión del delito de verter expresiones y ejecutado acciones deshonestas, y el Jurado lo negó.

El análisis cuantitativo y cualitativo del corpus de expedientes criminales indicó la formación de dinámicas y tendencias de funcionamiento del Jurado en la ciudad de Medellín entre 1821 y 1886. El Jurado transformó notablemente el funcionamiento del juzgado de circuito y significó la acción ciudadana en la construcción del derecho. La práctica del Jurado imprenta generó la reproducción y dinamización de principios y prácticas del Jurado que posteriormente impulsaron su ampliación en el orden. La publicidad de los juicios repercutió en el interés de los particulares dando lugar a que la institución se convirtiera en mecanismo difusor de principios cívico-políticos. Los debates sobre el Jurado se reprodujeron en la discusión judicial y legislativa, en la prensa y en publicaciones personales de querellas, su aumento era negativo para quienes el exceso de publicidad de las materias penales podía servir de 
escuela a los delincuentes. La participación popular en el Jurado implicó la sanción de veredictos que omitieron la legislación y que disminuyeron notablemente las penas siendo posible a través del mecanismo del veredicto. Las condenaciones menores de los delitos contra las personas, la anulación de acusaciones por delitos como amago, exceso de confianza, delitos contra la moral, y la reducción de las penas acorde con una visión de las circunstancias de los incriminados, indican la dinamización política generada por el Jurado.

\section{Conclusiones}

Este artículo ha puesto de presente tanto la capacidad del Jurado para generar una nueva comprensión y práctica del Derecho penal en la administración de justicia, como su centralidad en el proceso de democratización de la sociedad. En un modelo de Estado-nación basado en el principio de la soberanía popular el Jurado actuó de instrumento para hacer operativo dicho principio en el ámbito de la justicia. Este hecho significó en la práctica una matización de los efectos de una homogeneización legal que no siempre atendió a los valores y a las características de una población heterogénea. Ello fue posible por la capacidad que le fue otorgada a la institución para neutralizar e impulsar el Derecho a través de sus veredictos. El análisis de los expedientes judiciales de la ciudad de Medellín indicó que el Jurado no fue una institución fallida en Colombia como consecuencia de la complejidad étnica, cultural y regional o por la ausencia de una cultura jurídica. La institución produjo en los juzgados una dinamización jurídico-política que resultaba ajena al modelo procesal del ius commune y del absolutismo jurídico. Los elementos que la fundaron fueron: la participación popular, las garantías procesales como los sorteos y las recusaciones, y el tipo de justicia representativa sancionada a través de los veredictos. Asimismo, la tramitación de las sumarias por las autoridades judiciales ha indicado tendencias contrarias a la idea de que el Jurado era un mecanismo generador de dilaciones y demoras, de estructuras complejas que imposibilitaban la resolución de los procesos. El reduccionismo de este planteamiento pudo constatarse a partir del estudio de las acciones de los jueces, fiscales, escribanos y comisarios. Los expedientes indicaron un seguimiento estricto de los funcionarios tanto de las acciones procesales especificadas en la codificación procesal-penal como de las establecidas en las leyes orgánicas sobre el Jurado. Además se observaron en menor medida omisiones y errores, y otras carencias en el desempeño de las funciones. Así, sobre el mecanismo garantista del sorteo puede afirmarse que fue un mecanismo de estricto cumplimiento en las causas, su ejecución generó pocos inconvenien- 
tes a los procesos, y que se dieron escasas variaciones en su aplicación por parte de las autoridades judiciales. Respecto a la garantía de la recusación también se puede aseverar que fue dispuesta en todos los expedientes, y que su solicitud resultó corriente por parte de pleiteantes, defensores y fiscales. $\mathrm{Su}$ recurrencia es indicadora de la importancia de la acción como estrategia de enfrentamiento del juicio.

La garantía procesal de la defensa tuvo diferentes dinámicas que marcaron la definición de los procesos. El estudio minucioso de los abogados en el marco de los expedientes ha permitido identificar tres estrategias para enfrentar a los jurados, a través de las que lograron tanto absoluciones sobre delitos probados como reducciones de penas. Éstas se correspondieron con tres tipos de pruebas solicitadas por los defensores a los jueces: de conducta, de defensa y de acusación. Con la primera pretendieron demostrar la buena conducta del defendido, con la segunda la inocencia sobre el hecho imputado, y mediante la tercera alegaron la responsabilidad de víctimas o denunciantes en el delito. Para la ejecución de tales pruebas los abogados se valieron de interrogatorios a testigos. Pero si la acción de los abogados fue central en el tipo de la sanción impuesta a sus clientes, en la política de castigo establecida por el Jurado se advierte una marcada tendencia hacia la absolución de los incriminados y a la reducción de las penas. Ello no fue consecuencia directa de la incapacidad de los jurados o de su venalidad, como lo aseguraban los antijuradistas decimonónicos. Por el contrario, a través de los diferentes veredictos que plasmaron la «discrecionalidad» del Jurado frente al código pudo determinarse la incidencia de los procedimientos probatorios del delito y las rigurosas defensas de los abogados para neutralizar las sumarias. A ello hay que agregar otros elementos como el rechazo del Jurado a la rigidez de las leyes penales o su atención de las circunstancias particulares de los incriminados. El Jurado rechazó la aplicación del primer grado de la pena en la mayoría de casos y la negativa a la pena de muerte para el homicidio voluntario. Los veredictos condenatorios con aplicaciones penales reducidas expresaron políticas específicas de castigo cuyas variaciones fueron determinadas principalmente por las tipologías criminales. Para el caso de los delitos de hurto, robo y estafa la tendencia generalizada fue la del tercer grado, con la exclusión del delito de abigeato sobre el que hubo una tendencia a la aplicación del segundo grado. En cuanto a los veredictos por violencia contra las personas prevaleció la fijación del tercer grado, aún en los casos de heridas y riñas con arma peligrosa. Incluso los expedientes por heridas con agravantes indicados en la legislación, tampoco los jurados tuvieron demasiado en cuenta tal aspecto y sancionarían penas leves, siendo especialmente permisivos con los delitos de agresión física y sexual contra las mujeres. 
El Jurado contribuyó notablemente al proceso de construcción ciudadana colombiano (1821-1886) al convertirse en escuela jurídico política de la población difusora de principios y valores republicanos y también al servir como mecanismo de participación en la Justicia. Los juicios realizados en plazas, iglesias, alcaldías, juzgados, fueron importantes para difundir valores como la responsabilidad y la equidad. El primero se concretó cuando en los juicios los jurados estaban obligados a no abandonar la responsabilidad de emitir un veredicto sobre otro individuo: los ciudadanos al cumplir el cargo de jurados asumían un compromiso con el orden social y aminoraban el egoísmo individual de aquellos interesados exclusivamente en sus asuntos. El valor de la equidad en la práctica de la institución tenía lugar porque esta interiorizaba en los jurados una visión del otro como un igual en la medida en que: «cada uno, juzgando á su vecino, piensa que podrá él ser juzgado luego». En esta misma línea se consideraba que cuando el cargo de jurado era de fácil acceso a los ciudadanos servía para moderar la idea de inferioridad sentida por algunos de éstos o por sectores excluidos; al tiempo que podía limitar la idea de superioridad de otra clase de ciudadanos al verse sometidos ante tribunales populares.

Por otra parte, el ciudadano colombiano de mediados del siglo XIX a través del Jurado estrechó un vínculo con las instituciones del gobierno, y tuvo en él un compromiso con el gobierno y el orden de su vecindario. Es desde esta perspectiva que debe tenerse presente el valor político del Jurado en el siglo XIX. La hipótesis respecto a que el Jurado no podía tener potencial en Latinoamérica se quiebra cuando se identifica el sector popular mayoritariamente mestizo ejerciendo el cargo de Jurado. El Jurado basado como el voto en el ideario de la soberanía popular eliminó por tanto el estatus jurídico por estamentos y un tipo de juicio y de reglas particulares para cada grupo. Ser jurado fue un derecho político regido por el principio de mérito establecido a partir de la interacción entre deberes y derechos, y no por el de origen corporativo. La práctica del Jurado no implicó sin embargo, que los veredictos de los jurados no estuviesen condicionados por sus ideologías, prejuicios o consideraciones particulares sobre los incriminados.

\section{BibLIOGRAFÍA}

Arias, Alberto, "De la relación auto de proceder - veredicto - sentencia en juicios con jurados" (tesis doctoral), Bogotá, Pontificia Universidad Católica Javeriana, 1954.

Arroyo Padilla, Antonio, "Los jurados populares en la administración de la justicia en México en el siglo XIX”, Nueva época, 47 (Madrid, 2000): 137-169. 
Beccaria, Cesare, De los delitos y de las penas, París, René Masson, 1823.

Bentham, Jeremy, Tratados de legislación civil y penal, (traducida y comentada por Ramón de Salas bajo la dirección de José René Masson) 8 vols., París, Imprenta Masson e Hijos, 1823.

Bonaudo, Marta, "Aires gaditanos en el mundo rioplatense. La experiencia de los jefes políticos y el juicio por jurados en tierras santafesinas. (Segunda mitad del siglo XX)", Revista de Indias, 42 (Madrid, 2008): 255-280.

Camacho Roldan, Salvador, Memorias, 2 vols., Bogotá, Biblioteca Popular de Cultura Colombiana, 1946.

Carvalho, José, "Dimensiones de la ciudadanía en el Brasil del siglo XIX”, Hilda Sábato, Ciudadanía política y formación de las naciones. Perspectivas históricas en América latina, México, Fideicomiso de Historia de las Américas de El Colegio de México y Fondo de Cultura Económica, 1999: 321-344.

Clavero, Bartolomé, Razón de Estado, razón de individuo, razón de historia, Madrid, Centro de estudios constitucionales, 1991.

Clavero, Bartolomé, Happy Constitution. Cultura y lengua constitucionales, Madrid, Trotta, 1997.

Constant, Benjamin, Curso de politica constitucional, 3 vols., Madrid, Imprenta de la Compañía, 1820.

Cordovez Moure, José María, Reminiscencias de Santa Fé de Bogotá, Bogotá, Biblioteca Popular de Cultura Colombiana, 1946.

Donovan, James, Juries and the transformation of criminal justice in France in nineteenth and twentieth centuries, North Carolina, University of North Carolina, 2010.

Echeverri, Marcela, "Los derechos de indios y esclavos realistas y la transformación política en Popayán, Nueva Granada (1808-1820)”, Marta Irurozqui (coord.), Dossier violencia política en América Latina, siglo XIX, Madrid, CSIC, 2009: 45-72.

Escriche, Joaquín, Examen histórico-crítico de la institución del jurado, Madrid, Imprenta del Colegio Nacional de Sordos-Mudos, 1844.

Estado soberano de Antioquia, Constitución i leyes espedidas por la Asamblea Constituyente del Estado de Antioquia en sus sesiones ordinarias de 1856 i estraordinarias de 1857, Bogotá, 1857.

Fioravanti, Maurizio, Los derechos fundamentales. Apuntes de historia de las constituciones, Madrid, Trotta, 2003.

Fioravanti, Maurizio (ed.), El Estado Moderno en Europa. Instituciones y Derecho (traducción de Manuel Martínez Neira), Madrid, Editorial Trotta, 2004.

Flory, Thomas, El juez de paz y el jurado en el Brasil imperial, México, FCE, 1986. 
Galante, Mirian, "El primer liberalismo mexicano y la encrucijada de la representación. Reflejar la nación, gobernar el país. (México, 1821-1835)”, Historia crítica, 41 (Colombia, 2010): 134-157.

Galante, Mirian, "la historiografía reciente de la justicia en México, siglo XIX: perspectivas, temas y aportes", Revista complutense de historia de América, 37 (Madrid, 2011): 93-115.

Garapon, Antonine y Papadopoulos, Ioannis, Juzgar en Estados Unidos y en Francia, Bogotá, Editorial Legis S. A., 2006.

Garriga, Carlos y Lorente, Marta, Cádiz 1812. La constitución jurisdiccional, Madrid, CEPC, 2007.

Gómez, Santiago, Reflexiones sobre el jurado de conciencia, Bogotá, Ministerio de Justicia, 1989.

González, Florentino, Elementos de ciencia administrativa. Comprende el bosquejo de un sistema de administración pública para un estado republicano, 2 vols., Bogotá, Imprenta de J. A. Cualla, 1840.

González, Florentino, El juicio por jurados, breve noticia del origen y progresos del jurado del modo de practicar la prueba judicial en Inglaterra y los Estados Unidos comparado con el otras naciones y razones a favor de esta institución, Buenos aires, Imp., lit y fundición de tipos a vapor, 1869a.

González, Florentino, Elecciones de derecho constitucional, Buenos Aires, Imprenta de J. A. Bernheim, 1869b.

Grossi, Paolo, Mitología jurídica de la modernidad, Madrid, Trotta, 2003.

Hespanha, António Manuel y Serrano González, Antonio, Cultura jurídica europea: sintesis de un milenio, Madrid, Tecnos, 2002.

Infante, Carlos, El jurado (tesis de doctorado), Medellín, Imprenta de Uribe y Restrepo, 1892.

Irurozqui, Marta, La ciudadanía en debate en América Latina. Discusiones historiográficas y una propuesta teórica sobre el valor público de la infracción electoral, Lima, IEP, 2005.

Irurozqui, Marta, "El espejismo de la exclusión. Reflexiones conceptuales acerca de la ciudadanía y el sufragio censitario a partir del caso boliviano", Ayer, 70 (Madrid, 2008): 57-92.

Irurozqui, Marta y Galante, Mirian (eds.), Sangre de ley, Madrid, Polifemo, 2011.

Irurozqui, Marta; Galante, Miriam y Argeri, María, La razón de la fuerza y el fomento del derecho. Conflictos jurisdiccionales, ciudadanía y mediación estatal, Madrid, CSIC, 2011.

Jaksic, Iván y Posada-Carbó, Eduardo (comps.), Liberalismo y poder. Latinoamérica en el siglo XIX, Chile, FCE, 2011. 
Jaramillo, Joaquín Emilio, Juicio por jurados, Medellín, Imprenta oficial, 1935.

Jaramillo Uribe, Jaime, El pensamiento colombiano en el siglo XIX, Bogotá, Universidad de los Andes, 2001.

Jiménez, José Antonio, El proceso bio-psicológico del delincuente y la institución del jurado como tribunal de conciencia, Bogotá, Universidad Externado de Colombia, 1940.

Londoño Tamayo, Andrés Alejandro, "Una aproximación a la trayectoria de la literatura jurídica en Colombia en el siglo XIX", Revista Complutense de Historia de América, 37 (Madrid, 2011): 93-115.

Londoño Tamayo, Andrés Alejandro, "Juicios de imprenta en Colombia (1821-1851). El jurado popular y el control de los libelos infamatorios", Anuario Colombiano de Historia Social y de la Cultura, 40 (Bogotá, 2013): 75-112.

Malamud, Carlos; González de Oleaga, Marissa e Irurozqui, Marta (eds.), Partidos políticos y elecciones en América Latina y la Península Ibérica, II vols., Madrid, Fundación Ortega y Gasset, 1996.

Manin, Bernard, Los principios del gobierno representativo, Madrid, Alianza Editorial, 1998.

Martínez, Miguel, Criminalidad en Antioquia, Medellín, Imprenta del Espectador, 1895.

Melo, Jorge Orlando (ed.), Historia de Antioquia, Bogotá, Suramericana de seguros, 1988 .

Monarquía Española, Colección de los decretos y órdenes generales expedidos por las cortes ordinarias de las años de 1820 y 1821, en el segundo periodo de su diputación que comprenden desde el 25 de febrero hasta 30 de junio de último año, Tomo VII, Madrid, Imprenta Nacional, 1821.

Morelli, Federica, "Entre confianza y armas. La justicia local en Ecuador del antiguo régimen al liberalismo", Revista complutense de historia de América, 37 (Madrid, 2011): 27-47.

Muñoz Fernández, Francisco de Paula, El crimen del aguacatal, Medellín, Imprenta del Estado, 1874.

Nueva Granada, Leyes y decretos espedidos por el Congreso Constitucional de la Nueva Granada en el año de 1846, Bogotá, 1846.

Oldham, James, Trial by jury. The seventh amendment and anglo-american special juries, New York, University press, 2006.

Patiño Millán, Beatriz, Criminalidad, ley penal y estructura social en la provincia de Antioquia, 1750-1820, Medellín, IDEA, 1994. 
Phillips, Richard, De las facultades y obligaciones de los jurados, Madrid, Imprenta de Sancha, 1821. (Traducción al castellano del francés por Antonio Ortiz de Zarate y Herrera).

Piccato, Pablo, The Tyranny of Opinion: Honor in the Construction of the Mexican Public Sphere, Durham, Duke University Press, 2010.

Pinzón, Cerbeleón, Tratado de ciencia constitucional, Bogotá, Nicolás Gómez, 1839.

Posada-Carbó, Eduardo (ed.), Elections before democracy. The history of elections in Europe and Latin America, Londres, ILAS, 1996.

Quiñones Neira, Rafael, El jurado y su veredicto, Bogotá, Cuadernos de Difusión Jurídica, 1952.

Real, Antonio del, Elementos de derecho constitucional seguidos de un examen crítico de la constitución neogranadina, Cartagena de Indias, E. Hernández, 1839.

República de Colombia, Cuerpo de leyes de la República de Colombia, Caracas, Imprenta de Valentín Espinal, 1840.

República de Colombia, Código de procedimiento criminal de 1848, Bogotá, Imp, de M. S. Caicedo y compañía, 1848.

República de Colombia, Leyes, decretos i actos lejislativos espedidos por el congreso constitucional de la Nueva Granada en el año de 1851, Bogotá, Imprenta del Neo- Granadino, 1851.

República de Colombia, Leyes, decretos $i$ actos lejislativos de la nueva granada en el año de 1852, Bogotá, Imprenta del Neo-Granadino, 1852a.

República de Colombia, Censo general de población de la republica de la Nueva Granada de 1851, instruido por provincias, cantones, distritos, parroquiales $i$ aldeas; $y$ por edades y clases, $1852 \mathrm{~b}$.

República de Colombia, Constitución política de la Nueva Granada de 1853, Bogotá, Imprenta de Echeverría hermanos, 1853.

Restrepo Piedrahita, Carlos (comp. y prólogo), Actas del Congreso de Cúcuta, 3 vols., Bogotá, Biblioteca de la Presidencia de la República, 1989.

Sábato, Hilda (ed.), Ciudadanía politica y formación de las naciones. Perspectivas históricas en América latina, México, FCE, 1998.

Sala i Vila, Nuria "Justicia conciliatoria durante el liberalismo hispano en el Perú: el caso de huamanga", Marta Irurozqui (coord.), Dossier "Entre Lima y Buenos aires. Acción colectiva y procesos de democratización en Argentina, Bolivia y Perú, siglo XIX”, Anuario de estudios americanos, 69/2 (Madrid, 2012): 423-450.

Secretaría de Relaciones Exteriores, Estadística general de la Nueva Granada, Bogotá, 1846. 
Speckman Guerra, Elisa "El jurado para delitos comunes: leyes, ideas y prácticas (distrito federal, 1869-1929)", Salvador Cárdenas (ed.), Historia de la justicia en México (siglos XIX y XX), 2 vols., México, Suprema Corte de Justicia, 2005: 743-788.

Speckman Guerra, Elisa, "Los jueces, el honor y la muerte. Un análisis de la justicia (ciudad de México, 1871-1931)", Historia Mexicana, 4 (México, 2006): 14111466.

Speckman Guerra, Elisa, Crimen y castigo. Legislación penal, interpretaciones de la criminalidad y administración de justicia (ciudad de México, 1872-1910), México, UNAM, 2007.

Thibaud, Clément, Repúblicas en armas. Los ejércitos bolivarianos en la guerra de Independencia en Colombia y Venezuela, París/Caracas, Institut français d'études andines/Editorial Planeta Colombiana, 2003.

Tocqueville, Alexis, De la democracia en la América del norte, (traducida de la cuarta edición por D. A. Sánchez de Bustamante) Paris, 1837.

Uribe, María Teresa, "La política en Medellín, 1820-1845", Jorge Orlando Melo (ed.), Historia de Medellín, Bogotá, Sur Americana de Seguros, 1996: 175-188.

Uribe Vargas, Diego (comp.), Las constituciones de Colombia, 2 vols., Madrid, Ediciones Cultura Hispánica, 1977.

Fecha de recepción: 29 de mayo de 2015.

Fecha de aceptación: 26 de enero de 2016. 


\section{The People's Jury in Colombia in Ordinary Criminal Trials. Citizen Participation and Criminal Justice in Medellin (1821-1886)}

This paper provides an in depth study of the development of the People's Jury pertaining to ordinary criminal justice in Colombia, taking the Medellin circuit court (1821-18886) as a case study. Its main objective, based on a study focused on citizen participation trends and the procedural safeguards generated by the institution in the courts, is to explain how this court influenced social democratization and the transformation of criminal justice. The work is based on a variety of documentary sources, mainly criminal trials, and critical historiographic theorizations concerning citizens, law and justice within a Latin-American context.

KEY WORDS: people's jury; law; criminality; history of justice; judiciary branch; XIX century Colombia; Medellin. 